\title{
A SOCIOLOGIA PERIFÉRICA DE GUERREIRO RAMOS
}

\author{
João Marcelo Ehlert Maia*
}

\begin{abstract}
O artigo analisa a obra do sociólogo Alberto Guerreiro Ramos como parte do campo da sociologia periférica. Por meio de uma leitura interna de seus textos escritos na década de 1950, sugere-se que uma abordagem transnacional de sua produção intelectual pode contribuir para inserir a história do pensamento social brasileiro no campo da história global da sociologia no pós-Segunda Guerra Mundial.

PALAVRAS-CHAVES: Guerreiro Ramos. Sociologia periférica. História da sociologia. Pensamento social brasileiro.
\end{abstract}

O objetivo deste artigo é analisar o discurso sociológico de Alberto Guerreiro Ramos (1915-1982) a partir de duas dimensões relacionadas entre si: a) a história da sociologia periférica no período posterior à Segunda Guerra Mundial; b) a relação entre essa sociologia periférica e a história global da disciplina no mesmo período. Minha hipótese é que parte da produção intelectual de Guerreiro Ramos compartilha com essa sociologia um conjunto de teorias, conceitos e modos de pensar, o que implica reler a contribuição desse autor à luz de uma história alternativa ao campo exclusivamente nacional do chamado pensamento social brasileiro. Além disso, sustento que o caso de Guerreiro Ramos, visto por essa perspectiva ampliada, nos ajuda a recontar a própria história geral da disciplina de uma forma menos eurocentrada e mais propriamente global.

$\mathrm{O}$ artigo tem três seções. Na primeira, apresento brevemente o que entendo ser a sociologia periférica, mobilizando literatura relativa à história do conhecimento sociológico

\footnotetext{
* Doutor em Sociologia. Professor do CPDOC/Escola de Ciências Sociais da FGV. Pesquisador/bolsista do CNPq.

Praia de Botafogo 190/14 $4^{\circ}$ andar. Cep: 22250-900. Rio de Janeiro - Rio de Janeiro - Brasil. joao.maia@fgv.br
}

e dados recolhidos a partir de pesquisas que venho desenvolvendo nos últimos anos sobre o tema. Em seguida, analiso a produção sociológica de Guerreiro Ramos à luz desse universo, tomando como material primário principal alguns de seus principais textos da década de 1950, incluindo seu clássico livro sobre a redução sociológica. Finalmente, finalizo apontando como essa análise pode representar uma pequena, mas relevante, contribuição para novas questões que vêm sendo discutidas tanto no campo do chamado "pensamento social brasileiro" como nas pesquisas contemporâneas da história da sociologia.

As análises e as interpretações aqui apresentadas surgiram de diferentes pesquisas e reflexões realizadas no ambiente acadêmico do Centro de Pesquisa e Documentação de História Contemporânea do Brasil (CPDOC) da Escola de Ciências Sociais da Fundação Getúlio Vargas. Iniciei os estudos específicos sobre Guerreiro Ramos no âmbito do projeto "Terra, autonomia e imaginação periférica: descentrando o pensamento social brasileiro", financiado pela FAPERJ para o período compreendido entre 2010 e 2011. Mais recentemente, es- 
tou coordenando o projeto "Repertórios periféricos: léxicos, conceitos e teorias periféricas", financiado pelo CNPq para o biênio 2013-2014, e que é compartilhado com o pesquisador Cláudio Pinheiro, com o qual trabalhei no Laboratório de Pensamento Social (LAPES) do CPDOC.

\section{A SOCIOLOGIA PERIFÉRICA}

A categoria de sociologia periférica trabalhada neste artigo surgiu a partir da percepção de que a história da sociologia, tal como disseminada em livros, artigos e coletâneas especializadas, privilegia basicamente autores, teorias e correntes intelectuais surgidas nos Estados Unidos e na Europa, perpetuando, portanto, uma profunda assimetria entre contextos "centrais" e "periféricos", o que é um problema bem conhecido na literatura especializada. Não são poucos os estudos que reiteram as desigualdades estruturais existentes na geopolítica da produção de conhecimento (Hountondji, 1990; Alatas, 2006; Connell, 2007; Keim, 2010). Essas desigualdades contribuem para concentrar os recursos institucionais, econômicos e simbólicos necessários para a produção e circulação de conhecimento em países e universidades do Hemisfério Norte, lugar de onde são enunciadas as teorias ti-

$\stackrel{2}{7}$ das como legítimas e supostamente universais, స reservando-se aos países do Sul a função de \&

\& plina, que tem caráter notadamente eurocêntri-

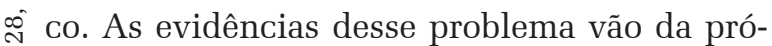

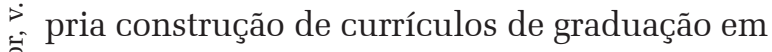
universidades brasileiras (nos quais os alunos são expostos, de forma excessiva e quase exclusiva, a disciplinas de introdução que relacio-

${ }^{1}$ A equipe é formada também pelos alunos de graduação Mariana Freitas (CPDOC, Escola de Ciências Sociais), Raphael Lebigre (UFRJ) e pela mestre em Filosofia pela USP Marianna Poyares. nam a sociologia ao pensamento europeu sobre a modernidade, por exemplo), aos próprios livros que organizam e sintetizam a visão hegemônica sobre essa história, como se pode ver nos trabalhos de Anthony Giddens e Jonathan Turner (1999) e Hans Joas e Wolfgang Knobl (2009), para ficar apenas em alguns dos nomes mais conhecidos no mainstream da disciplina.

Em geral, a narrativa contida nessas obras é bem conhecida: a história da sociologia no século XX teria conhecido seu momento fundador na grandiosa síntese de Talcott Parsons no livro A Estrutura da Ação Social, de 1937, momento em que a disciplina, nos EUA, teria incorporado, de forma decisiva, a teorização europeia. Em seguida, a consolidação do estrutural-funcionalismo nas décadas de 1940 e 1950 teria contribuído para a internacionalização do pensamento sociológico, sob a égide do par Parsons-Lazarsfeld. A crítica a essa síntese teria vindo da emergência das teorias de conflito e da renascença do marxismo, com larga contribuição de teóricos europeus (Dahrendorf, Rex, entre outros) nos anos de 1960. A proliferação de abordagens micro e macro, que não se comunicavam entre si (digamos, o estruturalismo de origem francesa e a abordagem dramatúrgica de Goffman), teria inspirado as novas tentativas de síntese teórica das décadas de 1970 e 1980, representadas nas obras de Pierre Bourdieu, Anthony Giddens e Jurgen Habermas, entre outros. Finalmente, a erosão de prestígio dos grandes paradigmas explicativos totalizantes teria impulsionado a pulverização de correntes teóricas, com a abertura da sociologia para a crítica feminista, para os estudos subalternos e para abordagens oriundas de outros campos, como psicanálise, antropologia e teoria literária. Essa história, resumida um pouco grosseiramente, aqui é contada tendo como geografia quase exclusiva os países do Atlântico Norte, o que torna toda a sociologia praticada na América Latina, na África e na Ásia irrelevante ou simples replicação ou recriação de uma história que lhes é alheia. Por isso, refiro-me aqui à sociologia periférica. 
Note-se que nem discuto a narrativa hegemônica sobre a história dos fundamentos tidos como "clássicos" da disciplina, que é responsável pela cristalização do famoso cânone que todo estudante de graduação aprende, formado pelos nomes de Marx, Weber e Durkheim. Como corretamente já apontou Raewyn Connell (2012), tal narrativa obscurece as profundas conexões entre o surgimento da reflexão sobre o social e fenômenos globais como o colonialismo e o imperialismo, que impulsionaram o olhar "imperial" que marcou Comte, Hohbouse e Spencer, entre outros nomes menos cotados e hoje esquecidos.

Mais recentemente, nota-se um esforço considerável no campo da história da sociologia, que tem por objetivo descentrar a narrativa acima apresentada, iluminando autores, instituições, teorias e correntes teóricas produzidas em contextos periféricos que contribuíram para modelar discursos e conceitos de grande circulação no pensamento social, mas que não são devidamente registrados e (ou) analisados na narrativa hegemônica. A já citada Raewyn Connell, por sua vez, vem empreendendo notável esforço na tentativa de inventariar e analisar pensadores africanos, asiáticos e latino-americanos que possam renovar o discurso teórico da disciplina (Connell, 2007), e a própria Associação Internacional de Sociologia vem abrindo espaço para essa discussão, tendo editado um valioso volume, no qual especialistas de diversas regiões do mundo apresentam a história da sociologia em países tão diversos como Irã, Palestina e África do Sul (Patel, 2009). No caso da América Latina, Fernanda Beigel (2013), Eduardo Deves (2006) e Claudio Pinheiro (2010) evidenciaram a circulação internacional da teoria da dependência e sua relevância para o processo de regionalização e transnacionalização da disciplina.

Minha pesquisa e este artigo sobre o caso de Guerreiro Ramos juntam-se a esse esforço, pois acredito que ainda há muito trabalho a ser feito, em especial no que se refere a abordagens comparativas e transnacionais. Trabalho com a hipótese de que a sociologia periférica, a despeito de sua notável diversidade interna, caracterizou-se pela existência de um campo internacional estruturado por um universo comum de questões relativas a problemas como autonomia, imperialismo, eurocentrismo, colonialismo e dependência. Em texto anterior (Maia e Caruso, 2012), exploramos a obra de um notável sociólogo periférico - Syed Hussein Alatas (1928-2007) - para evidenciar alguma das categorias que circulavam com desenvoltura nesse universo (como "mente cativa"). No que se refere ao vocabulário e às instituições que permitiam a circulação dessas questões, é importante notar que esse universo envolveu não apenas cientistas sociais, mas também economistas e historiadores de diferentes países, que escreviam em revistas e periódicos tais como a Cahiers Internationaux de Sociologie (editada na França entre 1946 e 2011), a América Latina (revista do Centro Latino-Americano de Pesquisa em Ciências Sociais da UNESCO), a Tiers-Monde (editada a partir dos anos 1960, também na França), e a africana Transitions, entre dezenas de outros títulos de menor regularidade e impacto. Finalmente, deve-se destacar a emergência de conferências e congressos de temática terceiro-mundista que proliferavam no período, mais particularmente na década de 1970 (Deves, 2006).

Uma das características principais desse vasto universo é o que nomeei como "linguagem da autonomia” (Maia, 2012a), isto é, um discurso sociológico que reconhece as assimetrias entre centro e periferia e busca refletir sobre esse tema, seja em termos práticos, impulsionando formas não acadêmicas de trabalho intelectual, seja em termos cognitivos, pelo desenvolvimento de novos conceitos que possam contribuir para a reelaboração da teoria sociológica. Sustento que Guerreiro Ramos pode ser interpretado como um intelectual cuja produção e trajetória ganha inteligibilidade à luz de questões próprias a esse universo transnacional, outrora conhecido como "Terceiro Mundo". Na próxima seção, procuro comprovar esse ponto. 


\section{GUERREIRO RAMOS E A SOCIOLO- GIA PERIFÉRICA}

Em outros artigos (Maia e Caruso, 2012; Maia, 2012a), esbocei as conexões entre Guerreiro Ramos e a sociologia periférica, e mais recentemente teci uma comparação entre o brasileiro e o sociólogo malaio Syed Hussein Alatas (1927-2008), um dos precursores da moderna ciência social no Sudeste Asiático (Maia, 2014). Essas comparações visavam a entender uma dimensão peculiar da trajetória intelectual de Guerreiro Ramos, que diz respeito às mudanças no seu discurso sociológico vivenciadas entre as décadas de 1940 e 1970. Neste artigo, amplio essa perspectiva, indo além do caso comparativo específico.

Na segunda metade da década de 1930, Guerreiro escreve para jornais e revistas (como O Imparcial, A Ordem, Norte, Cadernos da Hora Presente) e desenvolve intensa atividade de escrita, que é reunida na obra "Introdução à Cultura”. Nesse período, há pouca sociologia propriamente dita, já que o autor dedica-se à filosofia, à crítica cultural e à poesia, sempre motivado pelo existencialismo cristão que lhe é caro, e que se fundamenta na crítica à desumanização do homem moderno e na consequente busca por uma afirmação integral do sujeito. Filósofos como Maritain, Mounier e

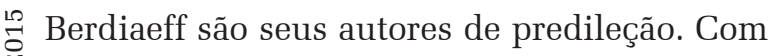

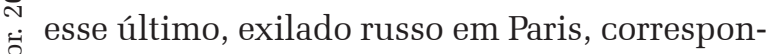
de-se por carta.

A sociologia começa a aparecer de forma mais decidida na escrita de Guerreiro após sua vinda ao Rio de Janeiro, em 1939. Na ocasião, § já fazia parte da administração Landulfo Alves \& na Bahia, e sua viagem para a capital federal de i̊ então visava à ampliação de sua formação intelectual. A despeito das fortes inclinações poéticas (o livro "O Drama de Ser Dois", com seus escritos da década de 1930, fora publicado em 1937), forma-se em Ciências Sociais (1942) e Direito (1943) na Faculdade Nacional de Filosofia, orientando-se a partir de então para a busca de afirmação profissional no incipiente campo científico do Rio de Janeiro. Após ter sua nomeação para a posição de assistente na cátedra de sociologia da FNFi preterida em favor de Costa Pinto, Guerreiro consegue obter um posto no Departamento Nacional da Criança em 1943, graças a San Thiago Dantas, e torna-se interino no DASP no mesmo ano. A partir daí, Guerreiro vai galgando posições no serviço público e orientando-se para o estudo e a aplicação dos métodos sociológicos nos processos de organização do trabalho e na administração pública.

Nos seus primeiros artigos mais propriamente acadêmicos, na Revista do Serviço Público, pode-se observar que o autor tinha um notável conhecimento sobre a sociologia norte-americana, em especial suas contribuições metodológicas para a disciplina. Assim, Ramos escrevia sobre técnicas de survey social, indicadores demográficos e organização do trabalho, entre outros temas de sociologia aplicada. Isso certamente refletia suas atividades no DASP e no Departamento Nacional da Criança, que foram investigadas por alguns de seus melhores intérpretes (Azevedo, 2006; Maio e Lopes, 2012). Nos anos de 1950 e 1960, surge o Guerreiro mais conhecido, autor de artigos incendiários sobre a alienação da sociologia brasileira, polemista notório por seu embate com Florestan Fernandes e membro indisciplinado do Instituto Superior de Estudos Brasileiros, o ISEB. Nesse período, conceitos como colonialismo, redução sociológica e alienação ganham espaço nos seus textos, bem como um conjunto novo de referências intelectuais, formado por pensadores do dito Terceiro Mundo. Finalmente, no seu longo exílio, vivido a partir de 1966 em solo norte-americano, na University of Southern California, encontraremos reflexões sobre administração e racionalização, com fundamentação em Habermas, Weber, Marcuse e outros autores europeus e americanos. É claro que se pode postular uma coerência na obra de Guerreiro Ramos, como notavelmente faz Ariston Azevedo (2006), ao apontar a constante preocupação crítica do 
autor com a alienação do homem moderno numa sociedade marcada pela racionalização, problema analisado à luz de uma agenda filosófica oriunda do existencialismo cristão. Porém, é também incontestável que, no período compreendido entre 1953 e 1964, essas preocupações foram vazadas em estilo, conceitos e citações que não eram exclusivas do autor, e nem poderiam se explicar pelo simples desenvolvimento interno do sistema intelectual brasileiro. Explico-me.

O primeiro ponto a se ressaltar é a centralidade do colonialismo na reflexão de Guerreiro Ramos nesse período. Longe de designar um período histórico específico, esse conceito é tratado pelo autor como intrínseco à estrutura epistemológica das ciências sociais. Assim, seus conhecidos textos sobre o "problema do negro" evidenciam como a própria construção da questão do negro no Brasil deriva de uma agenda das ciências sociais colonizadas, já que pressupõe que o "negro" seria membro de um grupo dotado de cultura e religião próprias, específicas de grupos "tradicionais", a ser investigado e analisado pelos cientistas brancos (Ramos, 1954). Longe de naturalizar o negro ontologicamente, Guerreiro Ramos relaciona a produção desse grupo ao próprio discurso das ciências sociais, que reitera uma posição subalterna. Como se vê, a crítica ao racismo é, na verdade, uma crítica às ciências sociais e ao seu discurso moderno. Esse movimento epistemológico não está necessariamente contido na sua produção anterior dos anos de 1940 (embora, obviamente, se possam apontar origens e rastros), mas ganha sentido se lido à luz dos escritos terceiro-mundistas que, na década de 1950, vinham evidenciando a dimensão colonial das ciências humanas europeias - caso de Frantz Fanon, por exemplo. A reflexão do autor também certamente se nutriu de sua experiência no Teatro Experimental do Negro (tem), fundado em 1944, e do Instituto Nacional do Negro, de 1949 (Barbosa, 2006). Nesses espaços, Guerreiro colaborava na organização das sessões de grupoterapia, que visavam a auxi- liar o chamado "homem de cor" a se integrar de forma plena na sociedade brasileira.

Essa virada periférica no pensamento de Guerreiro Ramos pode ser também explicada pelo encontro do autor com protagonistas da luta anticolonial em Paris, quando de uma viagem realizada em 1956. Na ocasião, a capital francesa era um verdadeiro centro da diáspora de intelectuais africanos e caribenhos das colônias, que logravam constituir laços de solidariedade transcontinental justamente no coração da Metrópole colonizadora. Guerreiro passa a escrever artigos para jornais defendendo o espírito de Bandung e inserindo os problemas brasileiros no tema mais geral da luta anti-imperialista e da situação do Terceiro Mundo. Essa viagem está descrita no artigo Centro e Periferia no Mundo, publicado em 11 de março de 1956 em O Jornal. Ao relatar suas impressões sobre a viagem, Guerreiro afirma:

O essencial dessas impressões diz respeito à politização desses povos até agora situados na periferia do mundo, ou seja, constitutivos do proletariado externo dos dois centros de poder de nosso tempo [...] Senti em Paris e Londres o que há de obstinado e decidido na ação de africanos e asiáticos em prol do soerguimento de suas regiões. A Conferência de Bandoemg (sic) e sua continuação no Cairo este ano, o próximo Congresso Mundial dos intelectuais de cor, a realizar-se em setembro vindouro em Paris, são apenas aspectos mais notórios de um trabalho cotidiano, ininterrupto [...]. (Ramos, 1956, p. 1)

Note-se, nesse artigo de jornal, a utilização do conceito de "proletariado externo", que foi consagrado na obra do pensador congolês Pierre Moussa. Mas, mesmo antes dessa viagem e desse texto, verifica-se, em Guerreiro, a forma pela qual temas que ele já trabalhava anteriormente - como o problema da alienação - começam a ser tratados a partir de uma perspectiva que enfatiza a inscrição periférica e subordinada do Brasil no mundo ocidental. Em seu texto "O processo da sociologia no Brasil: esquema para uma História das ideias" (Ramos, 1953), Guerreiro relê a tradição intelectual brasileira à luz de um esquema mais amplo 
que questiona o etnocentrismo e a dimensão imitativa do pensamento em países de origem colonial. Nas palavras do autor,

O ideal da sociologia universal nos países líderes do pensamento sociológico é, assim, um sintoma de etnocentrismo. Nos países culturalmente coloniais, é uma superfetação compensatória do complexo de inferioridade de certos elementos de elite (Ramos, 1953. p. 9).

Nessa mesma linha, Guerreiro afirma que países como Rússia, Índia, Japão e China teriam logrado transformar o conhecimento sociológico em instrumento de construção nacional, algo que não se deu propriamente no Brasil, ainda preso às determinações da situação colonial. Essa situação teria feito com que a produção intelectual no Brasil oscilasse entre o "imperialismo mimético" e o "caminho da afirmação”.

Se, por um lado, é antiga a linhagem de pensadores brasileiros que diagnosticara o caráter supostamente artificial e "importado" da vida intelectual brasileira (Brandão, 2005), é forçoso reconhecer que a linguagem e o vocabulário utilizados por Guerreiro Ramos para fazer esse mesmo ponto são novos. Há uma decidida abordagem geopolítica que coloca o problema da colonização e do eurocentrismo em lugar mais central do que, digamos, em Visconde do Uruguai ou em Alberto Torres, L 20 dois conhecidos pensadores associados a essa เ. vertente crítica. Pensadores não europeus estavam praticamente ausentes do horizonte deses homens, ainda fortemente orientados para tradição cultural europeia.

No ano de 1953, Guerreiro presidiu a sessão sobre estruturas regionais e nacionais no II Congresso Latino-Americano de Sociologia. Nessa sessão, apresentou várias teses que buscavam construir um sistema de relevância para as ciências sociais em países subdesenvolvidos ou em processo de desenvolvimento. Guerreiro desejava afirmar a necessidade da instrumentalização da sociologia para o processo de desenvolvimento das sociedades latino-americanas, o que exigiria a formação de uma agenda de pesquisas prioritária, na qual não haveria espaço para estudos monográficos ou estudos de comunidade. Suas teses acabaram sendo derrubadas no plenário final do evento, mas isso não impediu que o autor continuasse a defendê-las em outros espaços. No seu já citado livro sobre a história das ideias no Brasil, essas ideias são apresentadas, já que os exemplos apresentados de países que teriam logrado produzir uma tradição autêntica de sociologia (Rússia, Japão, China e Índia) são aqueles nos quais esse conhecimento teria se tornado combustível para afirmação nacional e construção dos países.

Outra evidência está no clássico livro de Guerreiro Ramos sobre a redução sociológica, de 1958 (Ramos, 1995). Nessa obra, o autor vale-se explicitamente da fenomenologia de Husserl para estabelecer um método de apropriação crítica de conceitos e teorias cunhados na Europa e nos Estados Unidos e utilizados largamente na teoria sociológica. Sua ideia principal é evidenciar como esse repertório deriva da experiência social e história dessas sociedades, embora tal origem seja apagada quando da sua apropriação por parte de cientistas sociais em contextos periféricos.

Essa abordagem fenomenológica poderia ser explicada com recurso da formação intelectual de Guerreiro Ramos, marcada pelo treinamento filosófico e pela intimidade com as correntes existencialistas. Porém o projeto da redução, tal como exposto pelo autor, não se limita à aplicação da fenomenologia, incorporando uma decidida marcação "periférica", pois Guerreiro dirige-se preferencialmente aos cientistas sociais de países em desenvolvimento. São esses intelectuais que se veem às voltas com o problema do falso universalismo de teorias e conceitos extraídos de outras realidades nacionais. A redução, portanto, não se explica como exercício de depuração conceitual apenas, mas, principalmente, como uma ferramenta para a produção de uma ciência social mais autônoma e menos alienada.

A marcação periférica é visível, por 
exemplo, nas referências mobilizadas por Guerreiro Ramos. Logo nos capítulos iniciais, o autor remete o leitor a Anta Diop, Mohamad Labadi e Aimé Césaire, conhecidos intelectuais periféricos de colônias francesas, todos às voltas com o problema do pensamento autônomo em condições de profunda assimetria entre centro e periferias. Além disso, as leis da redução sociológica, apresentadas nos capítulos subsequentes, enfatizam exatamente os procedimentos necessários para a superação do "pensamento imitativo", outro tema comum aos cientistas sociais e escritores que se viam às voltas com problemas teóricos e práticos similares nas suas regióes de origem. A primeira lei, por exemplo, intitula-se "Lei do comprometimento", e afirma a necessidade de engajamento do sociólogo com a sua realidade. Como se sabe, o tema do engajamento é próprio das filosofias existencialistas de diferentes matizes, mas a torção periférica operada por Guerreiro Ramos explica-se pela afirmação de que os cientistas, em países periféricos, devem se engajar nas suas realidades nacionais, e não em quaisquer realidades. A necessidade de afirmação nacional não era comum no pensamento sociológico do período no Hemisfério Norte, mas se configurava como tema fundamental para os intelectuais do Terceiro Mundo, às voltas tanto com processos de liberação nacional como com projetos de desenvolvimento autônomo em contextos já emancipados (Berger, 2004).

A terceira lei também guarda forte componente próprio da sociologia periférica. Essa lei, relativa à universalidade da ciência, afirma que tal universalidade se dá no nível abstrato da prática científica, referente aos procedimentos e teorizações mais gerais, mas não no nível da construção de problemas e objetos. Esses devem se originar do engajamento do cientista social com sua própria realidade e suas questões, o que aproxima Guerreiro Ramos de outros sociólogos que reconheciam a dimensão universal da ciência (e, portanto, rejeitavam a procura por teorias nativistas ou metodologias chauvinistas), porém criticavam a elaboração de agendas de pesquisa heterônomas. É o caso do já citado Syed Hussein Alatas, que sempre rejeitou tentativas de "islamizar o conhecimento", mas que apontou a necessidade de o sociólogo periférico elaborar um pensamento autônomo a partir de critérios de relevância que são estabelecidos localmente (Alatas, 1972).

No seu exílio nos Estados Unidos, iniciado em 1966, Guerreiro Ramos volta ao trabalho intelectual intenso, tendo lançado vários artigos e livros. Nessa fase final de sua trajetória, seus escritos orientam-se mais detidamente para a teoria das organizações, retomando preocupações há muito acalentadas - como o problema da alienação em sociedades modernas - e mesmo problemas desenvolvidos na década de 1960, como a questão da produção autônoma de conceitos e teorias mais ajustados à realidade nacional (Ramos, 1966; 1981). Porém tais textos já não mobilizam, de forma mais extensa, referências, conceitos e intelectuais oriundos do campo da sociologia periférica, como no período anterior, analisado acima. Em outra ocasião (Maia, 2012b), argumentei justamente que a produção sociológica de Guerreiro nos EUA demonstrava notável conhecimento da discussão teórica feita no Hemisfério Norte, seja da tradição funcionalista norte-americana (Parsons e Shills, por exemplo), seja da teoria crítica europeia (citações de Habermas). Com isso quero dizer que, a despeito de ser possível identificar temas e problemas perenes na obra de Guerreiro, é inegável que houve, nos anos de 1950 e 1960, uma "torção periférica".

Foi justamente esta torção que explorei, por acreditar que ela explica a forma como Guerreiro se engaja num universo intelectual que denominei aqui de "sociologia periférica". Porém sustento também que tal análise não serve apenas para produzir mais uma nova interpretação do autor em tela, mas também nos permite vislumbrar outro modo de pensar a história intelectual brasileira como um todo, 
ou, dizendo de outra maneira, nosso "pensamento social”, além da própria história global da sociologia. Explico-me.

\section{Implicações analíticas para o pensa- mento social brasileiro e a história global da sociologia}

Os estudiosos que se dedicam à pesquisa das ideias e dos intelectuais brasileiros já exploraram, de forma sofisticada e produtiva, as conexões internas nesse universo nacional. Numa perspectiva que se tornou clássica na área, Luiz Werneck Vianna (1997) consolidou uma agenda baseada na identificação de tradições "americanistas" e "iberistas" na vida intelectual brasileira, aproximando, por exemplo, autores de épocas diferentes como Oliveira Vianna e Visconde do Uruguai. Em outro percurso, Gildo Brandão (2005) estabeleceu a hipótese das "linhagens" do pensamento político brasileiro, também construindo famílias intelectuais em termos diacrônicos. A perspectiva avançada aqui e em textos anteriores (Maia, 2009; 2013; 2014) parte desses avanços, mas sugere que também podemos interpretar nosso pensamento social como parte de um amplo campo transnacional que reunia intelectuais, instituições, categorias, conceitos e obras, que 늘 destacavam outros temas para a agendada sociologia, tais como imperialismo, colonialis- mente vinculado com o estudo das ideias modernas sobre o social. De certa maneira, essa separação reflete a polêmica em torno do estatuto científico dos textos agrupados na rubrica do "pensamento social", polêmica que motivou boa parte das discussões constitutivas desse campo, mas que não me cabe retomar aqui.

É certo que tal reflexão não é inédita, já que não foram poucos os pesquisadores que empreenderam estudos comparativos ou de recepção para evidenciar as conexões internacionais que explicam ideias e atitudes de pensadores e intelectuais brasileiros. Novamente, os próprios estudos de Werneck Vianna, já citados, tomam como marcação a inscrição periférica do Brasil na formação do mundo ocidental, o que explica o tipo de recurso que o autor faz da obra do italiano Antonio Gramsci. Barboza Filho (2000), por sua vez, fez discussão similar, ao construir um vasto universo cognitivo pautado pelo conceito de "barroco", cuja origem não é nacional, mas sim própria da formação histórico-cultural do mundo ibero-americano. Em outra tradição intelectual, tributária do marxismo acadêmico paulista (Lahuerta 1999), o conceito de "periferia" foi fundamental para articular interpretações sobre o lugar das ideias dominantes na formação da sociedade brasileira (Schwartz, 1973; Ricupero, 2008). Finalmente, no próprio caso de Guerreiro Ramos, não são poucos os intérpretes que buscaram evidenciar a conexão terceiro-mundista como chave analítica (Ortiz, 1985; Motta, 2010).

Parto das contribuições acima para sugerir a existência do campo da sociologia periférica como um universo pleno de significância e potência, no qual se devem inscrever aspectos da produção intelectual no Brasil. Isto é, trata-se de "ver o nacional de fora para dentro", por assim dizer, e não simplesmente adicionar a dimensão internacional.

Finalmente, tal ângulo de análise também pode contribuir para um reenquadramento da própria forma como contamos a história global da disciplina de sociologia. Na primeira 
parte deste artigo, expus as críticas que vêm sendo feitas recentemente ao eurocentrismo que marca as narrativas hegemônicas nessas pesquisas. Porém, é imperioso reconhecer que tais narrativas vêm sendo questionadas até mesmo nos países centrais no Atlântico Norte. Por exemplo, já se apontou o quanto ainda se ignora o papel fundamental de sociólogas mulheres, como Harriet Martineau (Deegan, 2003), e mesmo Jennifer Platt, uma decana da sociologia britânica, argumentando sobre a necessidade de investigarmos a imensa pluralidade que constituiu o universo do que conhecemos hoje por sociologia (Platt, 2010).

Tais contribuições derivam, ao menos parcialmente, da renovação do campo da história da sociologia, no qual novas abordagens vêm, desde meados da década de 1970, investigando mais detidamente as circunstâncias que presidiram a formação de cânones, trajetórias consagradas e tradições intelectuais. Trabalhos como os de Stephen Lukes (1973) e Terry Clark (1973) abriram esse caminho, cuja síntese programática pode ser encontrada no artigo de Jones (1983), no qual as contribuições do contextualismo linguístico da Escola de Cambridge e da nova história da ciência (via Thomas Kuhn) são reclamadas para os estudos sobre história da sociologia. Essa nova onda de pesquisas foi marcada, por um lado, por uma ênfase maior no rigor historiográfico e na pesquisa documental, como se pode verificar no conhecido trabalho de Jennifer Platt sobre a história da metodologia nos Estados Unidos (Platt, 1996), e, por outro, pelo interesse em desvendar as variáveis institucionais e políticas que modelaram o cânone da disciplina, seus "eleitos" e seus "esquecidos" (Lamont, 1987; McLaughlin, 1988; Baher, 2002).

Nos últimos anos, esse campo tem se aberto para pesquisas transnacionais e comparativas, que procuram evitar as narrativas excessivamente encapsuladas no paradigma do Estado-Nação (a obra de Wolf Lepenies talvez seja a mais potente herdeira dessa perspectiva "nacionalista"). Assim, os pesquisadores no campo da história da sociologia têm chamado a atenção para a importância de agências de cooperação internacional (Heilbron, Guilhot e Jeanpierre, 2008) e para a migração de conceitos entre diferentes contextos nacionais (Schrecker, 2010).

Faltam, porém, estudos que não se limitem ao universo da sociologia nos Estados Unidos e na Europa. De forma geral, o conhecimento sobre a história da disciplina, embora cada vez mais sofisticado e detalhado, ainda se ressente do foco excessivo na produção intelectual do Hemisfério Norte. Pouco se sabe sobre a circulação da teoria da dependência entre os anos de 1970 e 1980, por exemplo, que tanto impacto teve na consolidação de redes intelectuais entre cientistas do Hemisfério Sul (Pinheiro, 2010; Vedes, 2006) e na própria produção de políticas públicas (Macedo, 2013).

Nesse sentido, uma obra como a de Guerreiro Ramos lança luz nova sobre como sociólogos do dito Terceiro Mundo lidavam com o mainstream da disciplina de maneiras criativas e inusitadas. O conceito de redução sociológica, tal como trabalhado pelo autor na sua obra clássica de 1958, pode nos ajudar a recontar não apenas a produção teórica feita fora dos grandes centros, mas a própria história do pensamento fenomenológico nas décadas de 1950 e 1960. Além disso, boa parte da discussão contemporânea sobre colonialidade e pós-colonialidade ainda tem marcações quase que exclusivamente oriundas do universo linguístico anglo-saxão, e os pensadores usualmente relacionados às discussões dos anos de 1950 e 1960 são, em sua maioria, poetas, filósofos e escritores (como Frantz Fanon, Aimé Césaire, Albert Memmi etc.).

Dito de outra forma: o caso de Guerreiro Ramos não deve ser visto como exemplar apenas da sociologia brasileira, embora ele, obviamente, o seja, mas sim como o de um intelectual relevante na produção de uma sociologia feita em contexto periférico, que dialogou e partilhou os campos semântico e político, além de horizontes epistemológicos, 
com outros intelectuais da América do Sul, da África, ou da Ásia. Essa abordagem transnacional deve servir para reequacionar a forma de narrar o desenvolvimento de nossa disciplina. Por exemplo: é possível contar uma história da sociologia da modernização que ignore a crítica reconstrutiva feita por Costa Pinto, Florestan, Gino Germani e outros, na América Latina (Brasil Junior, 2013)? É possível fazer uma história sincera do marxismo no pós-Segunda Guerra que desconsidere a teoria da dependência e seus efeitos em certos departamentos de economia e política nos anos de 1970 e 1980? É possível contar uma história da discussão epistemológica sobre o estatuto da objetividade nas ciências sociais sem entender o debate sobre as indigenous sociologies nos anos de 1980 (Akiwowo, 1986)? É possível termos uma história da metodologia em sociologia ignorando a contribuição do colombiano Orlando Fals Borda para a pesquisa em ação?

Todos esses exemplos apontam para a necessidade de pensar a história global da sociologia levando em conta as experiências periféricas não apenas como campos nos quais a grande teoria foi aplicada, mas como espaços a partir dos quais essa teoria foi consumida, recriada e revertida, contribuindo, portanto, para outra visão do que foi nossa disciplina.

Recebido para publicação em 20 de fevereiro de 2014 Aceito em 11 de dezembro de 2014

\section{REFERÊNCIAS}

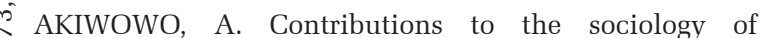

\& knowledge from an African oral poetry. International Sociology, v. 1, n. 4, p. 345-358, dez., 1986.

ALATAS, S.F. Alternative Discourses in Asian Social Science: Responses to Eurocentrism. New Delhi: Sage, 2006.

ALATAS, S.H. The Captive Mind in Development Studies. Some Neglected Problems and the Need for an Autonomous Social Science Tradition in Asia. International Social Sciences Journal. v. 24, n. 1, p. 9-25, 1972.

AZEVEDO, A. A Sociologia Antropocêntrica de Alberto Guerreiro Ramos. 2006. Tese. Programa de Pós-Graduação em Sociologia Política/ UFSC. Florianopólis.
BAHER P. Founders, Classics, Canons. Modern Disputes over the Origins and Appraisal of Sociology's Heritage. New Jersey: Transaction Books, 2002.

BARBOSA, M. Guerreiro Ramos: o personalismo negro. Tempo Social, São Paulo, v. 18, n. 2, p. 217-228, nov., 2006.

BARBOZA FILHO, R. Tradição e artifício: o barroco na formação americana. Belo Horizonte: Editora UFMG, 2000.

BEIGEL, Fernanda (Org). The politics of academic autonomy in Latin America. Farnham, Ashgate, 2013.

BERGER, Mark T. After the third world? History, destiny and fate of the Thirdworldism. Third world quarterly. v. 25, n. 1, p. 9-39, 2004.

BRANDÃO, G.M. Linhagens do pensamento político brasileiro. Dados - Revista de Ciências Sociais, Rio de Janeiro, v. 48, n. 2, p. 231-269, 2005.

BRASIL JUNIOR, Antônio. Passagens para a teoria sociológica: Florestan Fernandes e Gino Germani. São Paulo: HUCITEC, 2013.

CLARK, T.N. Prophets and Patrons: the French University and the emergence of the Social Sciences. Cambridge: Harvard University Press, 1973.

CONNELL, R. Southern theory: the global dynamics of knowledge in social science. London: Polity Press, 2007.

. O Império e a criação de uma ciência social. Contemporânea, São Carlos. v. 2, n. 2, p. 309-336, 2012.

DEEGAN, Mary Jo. Textbooks, the history of sociology and the sociological stock of knowledge. Sociological theory. v. 21, n. 3 p. 295-308, Set. 2003.

DEVES, E. Los cientistas econômico sociales chilenos em los largos 60 y su inserción em las redes internacionales: la reunión del foro tercero mundo em Santiago em abril de 73. Revista Universum, Talca/Chile v. 21, n. 1, p. 138167. 2006

GIDDENS, Anthony; TURBER. Jonathan. Teoria social hoje. São Paulo: UNESP, 1999.

HEILBRON, Johan; GUILHOT, Nicolas; JEANPIERRE, Laurent. Toward a transnational history of the social sciences. Journal of the history of the behavioral science. v. 44, n.2, p. 146-60. 2008.

HOUNTONDJI, Paulin. Scientific Dependence. Africa Today. Research in African Literatures. Bloomington. v.21, n. 3, p. 5-15, 1990.

JONES, R.A. The new history of sociology. Annual Review of Sociology. Palo Alto, v. 9, p. 447-69. 1983

JOAS, Hans; KNÖBL Wolfgang. Social theory. Twenty introductory lectures. Cambridge: Cambridge University Press, 2009.

KEIM, Wiebke. Pour une Modèle Centre-Périphérie dans la science sociale. Aspects problematiques des relations internationales en sciences sociales. Revue dês anthropologies des connaissances. Paris, v. 43, n. 3, p. 57098. 2010.

LAHUERTA, Milton . Intelectuais e transição: entre a política e a profissão. Tese. Doutorado em Ciência Política, Faculdade Filosofia Letras e Ciências Humanas - USP, São Paulo. 1999

LAMONT, M. How to become a dominant french philosopher: the case of Jacques Derrida. The American Journal of Sociology. Chicago, v. 93, n. 3, p. 584-622. 1987

LUKES, Steven. Émile Durkheim: his life and work. London: Penguin Press, 1973.

MACEDO, Felipe. B. Dependência em trânsito: recepções e reinterpretações do pensamento da CEPAL e da Teoria da Dependência em África - o caso Tanzânia. Monografia apresentada como requisito para conclusão de Bacharelado 
em Ciências Sociais na Escola Superior de Ciências Sociais da FGV. Rio de Janeiro, 2013.

MAIA, João Marcelo Ehlert. Pensamento brasileiro e teoria social: notas para uma agenda de pesquisa. Revista Brasileira de Ciências Sociais. São Paulo, v. 24, n. 71, p. 155-168, 2009.

; CARUSO, Gabriela B. Uma trajetória intelectual periférica: Hussein Alatas e a sociologia autônoma. Perspectivas: Revista de Ciências Sociais. São Paulo, v. 41, p. 53-77, jan./jun. 2012.

The transnational language of autonomy in the Global South: the Works of A. Guerreiro Ramos e S.Hussein Alatas. Paper apresentado no seminário intermediário do Research Committee on the History of Sociology. Dublin, 27-30 junho de 2012a.

- Reputações à brasileira. O caso de Alberto Guerreiro Ramos. Sociologia \& Antropologia, Rio de Janeiro, v. 2, n. 4, p. 265-291, 2012. 2013(b).

. Além da pós-colonialidade: a sociologia periférica e a crítica ao eurocentrismo. Cadernos de Estudos Culturais, Campo Grande, v. 5, n. 9, p. 81-92, 2013.

. History of sociology and the quest for intelectual autonomy in the Global South: the cases of Alberto Guerreiro Ramos and Syed Hussein Alatas. Current Sociology.v. 62, n. 7, p. 1097-1115. 2014.

MAIO, Marco Chor; LOPES, Thiago da Costa. Da Escola de Chicago ao Nacional-Desenvolvimentismo: Saúde e Nação no pensamento de Alberto Guerreiro Ramos (1940-1950) Sociologias. Porto Alegre, v. 14, n. 30, p. 290-329, 2012.

McLAUGHLIN, Neil. How to become a forgotten intellectual: intellectual movements and the rise and fall of Erich Fromm". Sociological Forum, v. 13 n. 2, p. 215-46. 1998.

MOTTA, Luiz Eduardo. A Política do Guerreiro: Nacionalismo, revolução e socialismo no debate brasileiro dos anos 1960. Organizações \& Sociedade, Salvador v.17, n. 52, p. 85-101, 2010.

ORTIZ, Renato. Cultura brasileira e identidade nacional. São Paulo: Brasiliense, 1994

PATEL, S. The ISA Handbook of diverse sociological traditions. London: Sage Publications, 2009.
PINHEIRO, C. Direct and indirect transitivity. The receptions of dependency theory. In: India and Singapore and other dialogues between intellectual peripheries from the Global South. World social sciences and humanities network meeting. 28-30th October, Buenos Aires, Argentina, 2010.

PLATT, Jennifer. Sociology. In: Backhouse R.; Fontaine $\mathrm{P}$. (eds). The history of the social sciences since 1945. Cambridge: Cambridge University Press, 2010.

. A history of sociological research methods in America. 1920-1950. Cambridge: Cambridge University Press, 1996.

RAMOS, Alberto Guerreiro. O Processo da Sociologia no Brasil (esquema de uma História das Ideias). Rio de Janeiro: Estúdio de Artes Gráficas, 1953.

. O problema do negro na sociologia brasileira. Cadernos do Nosso Tempo. Rio de Janeiro . v. 2, n. 2, jan/ jun1954.

. Centro e periferia no mundo. O Jornal, Rio de Janeiro. Publicado em 11 de março de 1956.

A redução sociológica (introdução ao estudo da razão sociológica). Rio de Janeiro: Editora da UFRJ, 1995.

. Administração e estratégia do desenvolvimento. Elementos de uma sociologia especial da Administração. Rio de Janeiro: Editora FGV, 1966.

The new science of organizations: a reconceptualization of the wealth of nations. Buffalo, NY: University of Toronto Press, 1981.

RICUPERO, Bernardo. Da formação à forma: ainda 'as ideias estão fora do lugar. Lua Nova, São Paulo, n. 73, p. 59-69, 2008

SCHRECKER, Cherry. Community and community studies: a retourn journey. In __. (Org). Transatlantic voyages and sociology: the migration and development of ideas. Furnham: Ashgate, 2010.

SCHWARTZ, Roberto. As ideias estão fora do lugar. Estudos CEBRAP, São Paulo, v. 3, p.151-161, 1973. 


\section{THE PERIPHERAL SOCIOLOGY OF GUERREIRO RAMOS}

João Marcelo Ehlert Maia This article analyzes the works by sociologist
Alberto Guerreiro Ramos as a part of the field of peripheral sociology. From an internal reading of his texts written in the 1950s, we suggest that a transnational approach of his intellectual output may contribute to inserting the history of Brazilian social thought in the field of the global history of post-WWII sociology.

Keywords: Guerreiro Ramos. Peripheral sociology. History of sociology. Brazilian social thought.

\section{LA SOCIOLOGIE PÉRIPHÉRIQUE DE GUERREIRO RAMOS}

João Marcelo Ehlert Maia

Larticle analyse l'oeuvre de Alberto Guerreiro Ramos en tant que partie du champ de la sociologie périphérique. Par une lecture interne de ses textes écrits dans les années 1950, nous partons de l'hypothèse selon laquelle une approche transnationale de sa production intellectuelle peut contribuer à insérer l'histoire de la pensée sociale brésilienne dans le champ de l'histoire mondiale de la sociologie post Deuxième Guerre Mondiale.

MotS-CLÉs: Guerreiro Ramos. Sociologie périphérique. Histoire de la sociologie. Pensée sociale brésilienne.

João Marcelo Ehlert Maia - Doutor em Sociologia. Professor adjunto do CPDOC/FGV-RJ. Área de maior ênfase de estudo é Sociologia da Cultura, atuando principalmente nos seguintes temas: intelectuais, pensamento social brasileiro e história das ciências sociais. Recentemente tem explorado o campo da teoria social em contextos periféricos (pós-colonialismo, decolonialidade e pensamento social periférico). Faz parte de dois grupos de pesquisa reconhecidos pelo CNPq: Epistemologias Fronteiriças e Conexões Sul-Sul (sediado na UNB) e Intelectuais e Poder no mundo Ibero-Americano (sediado na UERJ). Membro do grupo de trabalho em História da Sociologia da ISA (Research Committe on the History of Sociology) onde exerce a função de secretário. Publicações recentes: Protests, protests, everywhere. The Cairo review of global affairs, v. 12, p. 79-86, 2014; History of sociology and the quest for intellectual autonomy in the Global South: the cases of Alberto Guerreiro Ramos and Syed Hussein Alatas. Current Sociology (Print), v. 62, p. 1097-1115, 2014; Qual sociologia pública? uma visão a partir da periferia. Lua Nova (Impresso), v. 87, p. 83-112, 2013; Além da pós-colonialidade: a sociologia periférica e a crítica ao eurocentrismo. Cadernos de Estudos Culturais, v. 5, p. 81-92, 2013. 